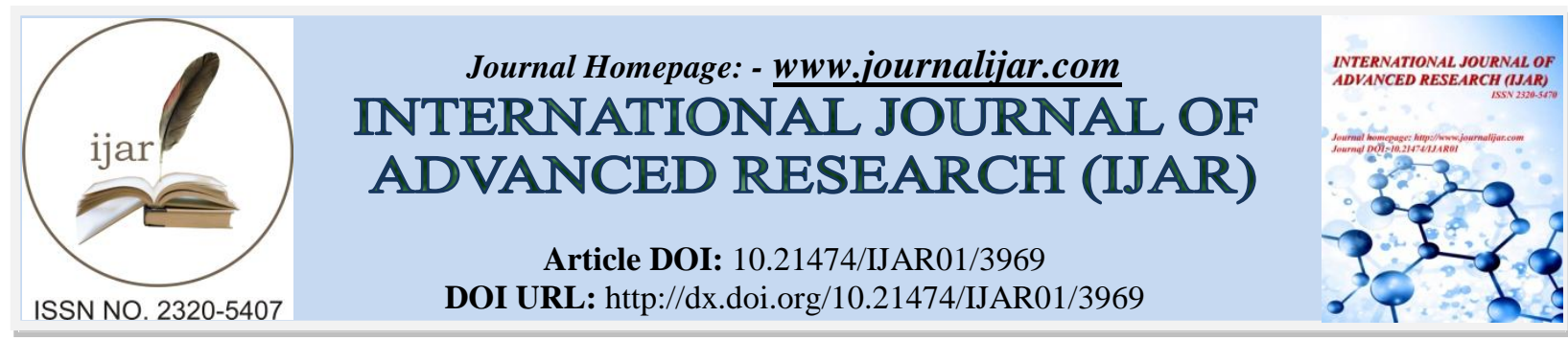

RESEARCH ARTICLE

\title{
LEVEL OF STRESS AMONG STAFF NURSES WORKING IN EMERGENCY AND GENERAL WARDS OF SKIMS HOSPITAL; A COMPARATIVE STUDY.
}

Firdousa jan.

Madr-e-Meharban Institute of Nursing Sciences and Research, Deemed university SKIMS Soura Srinagar Kashmir.

\section{Manuscript Info}

Manuscript History

Received: 18 February 2017

Final Accepted: 09 March 2017

Published: April 2017

Key words:-

level of stress, emergency wards, general

wards, hospital, staff nurses.

\section{Abstract}

Background: Workplace Stress among nurses is a global problem. The success in delivering quality patient care depends on the efficiency and motivation of the nursing personnel. Stress has become one of the most serious health issues in the modern world. Emergency nurses deal with many challenges which cannot be predicted including sudden death of patients, trauma patients, overcrowding, witnessing aggression, violence etc. There can be many factors that helps to explain why nurses working in emergency wards have higher level of stress than nurses working in general wards, but before assessing the factors causing stress it is important to become aware of whether the nurses are perceiving stress or not.Aim: The aim of this study was to assess the level of stress among staff nurses working in emergency and general wards of SKIMS Hospital. Material and methods: A comparative descriptive design was used. Sample of 120 staff nurses were selected randomly from the list of 356 staff nurses working in the SKIMS hospital with the use of a probability simple random sampling technique. Perceived stress scale was used for measuring stress level among staff nurses. Results: In emergency wards 30 (50\%) of staff nurses had severe level of stress, whereas $27(45 \%)$ of staff nurses had moderate level of stress and 3(5\%) were under mild level of stress, while as in general wards majority $39(65 \%)$ of staff nurses had moderate level of stress scores, whereas $12(20 \%)$ were under severe level of stress scores and $9(15 \%)$ were under mild level of stress. So, there is significant difference in level of stress between staff nurses working in emergency and general wards $(\mathrm{P}=0.002<$ 0.05).Conclusion; In emergency wards majority of staff nurses had severe level of stress whereas in general wards majority of staff nurses had moderate level of stress. High levels of stress result in staff burnout and turnover and adversely affect patient care.

Copy Right, IJAR, 2017,. All rights reserved.

\section{Introduction:-}

Today, mental disorders stand among the leading cause of disease and disability in the world. One in four (25\%) people in the world will be affected by mental or neurological disease at some point in their lives. Being 'stress' as a universal phenomena reflecting in each aspect of life cycle, was identified as a major cause of attrition among all categories of people. ${ }^{1}$ 
Stress affects the physical and emotional wellbeing of people. stress varies with age, gender, mental capacities and environmental conditions of people. stress can be defined as a process, which causes individual to believe that they are not able to cope up with the situations they are facing with. When the level of stress increases the person feels anxious, tense, frustrated, and angry with the result they fail to recognize in some ways and the situation gets out of control.

Psychological factors, in addition to physical, chemical and biological risks at the job environment are the main dangerous factors and job stress is very important among psychological disorders. United Nation (UN) in 1992 declared that job stress is the disease of 20th century and later, World Health Organization stated that it is epidemic. The International Organization of Labor, estimated the detriment caused by job stress, about $1 \%-3.5 \%$ of national gross production. In different researches it has become clear that about $30 \%$ of labors of developed countries have job stress disorder. ${ }^{2}$

Job stress exists in all professions but health care professionals appear to be at particular risk because they face demands which are higher than other occupations with the result they have high level of stress. Job stress effects on nurses physical and mental health.

Throughout the world, research has shown that work-related stress is a significant problem and represents a major challenge to occupational health. Individuals and organizations struggle to keep up with, and ultimately bow to the dramatically changing nature of work due to globalization of the economy, the use of new information and communication technology, growing diversity in the workplace, and an increased mental workload. Work-related stress is a common and costly problem that leaves few workers untouched. ${ }^{3}$

A survey by the national association of the working men, USA 1994 reported that $38 \%$ perceived nursing as very stressful, $62 \%$ perceived as moderately stressful. It is usually observed that nursing professionals undergo tremendous stress in their workplace. A study conducted in Mumbai on job stress perception among nurses concluded, $50 \%$ of the nurses working in OT experienced moderate stress, $70 \%$ of the nurses working in ICU'S experienced very severe stress and $76.61 \%$ of the nurses working in wards experienced severe level of stress. ${ }^{4}$

Many aspects of the health care requires 24 hours coverage, necessitating some form of shift work. Among the Nation's full time health care workers $30.1 \%$ are shift workers, $10.8 \%$ of them work in evening shifts, $9.4 \%$ work in night shifts, $3.3 \%$ work in rotating shifts. ${ }^{5}$

Current evidence suggests that health care professionals have higher absence and sickness rates than staff in other sectors. it was also found that $27 \%$ of health care staff suffered serious psychological disturbances compared with $18 \%$ of general working population. It has been suggested that stress may be reason for nurses leaving their jobs. Thus, the problem of retaining qualified and experienced staff has highlighted the need to look at various aspects of work and the work environment, which affects the level of job satisfaction and in turn influences quality of service and help to the health system to cater the needs of community effectively. ${ }^{6}$

Even though everyone experiences stress, research has shown that nurses, especially has numerous stressors that affect their daily grind. Many factors come into play periodically such as clinical workload, role conflicts, family and social relationships, job satisfaction, physical and psychological health problems. These are just a few of the sources that could possibly cause stress, hence there has been a growing awareness about the problems of nurses which leads to the severe stress among them and which requires adequate coping behavior to deal with the situation.

There is a growing need for reasonable and practicable guidance in relation to the management of work related stress, coping and health. To be effective such guidance must both reflect a scientifically valid approach to stress and stress management and be tailored to the specific needs and context implied in dealing with particular work organization and groups. ${ }^{7}$

Nurses in hospital settings face conditions of overload, job insecurity, low satisfaction in job, lack of autonomy hence workplace stress is a growing concern in the current state of economy. Workplace stress has negative impact on productivity and profit of an organization. 
Organizations can take measures to alleviate the negative impact of stress. on individual basis nurses need to learn to recognize the signs that indicate they are feeling stressed out, and employers of the organization need to be aware of the negative effects of stress on nurses health as well as organizations profit.

A large part of the problem of stress related mental illness is that there is a general lack of understanding - as well as action - on mental health issues in the workplace. This can be aggravated by employee's reluctance to seek help. Furthermore, there remains a stigma associated with mental illness, and this may prevent employees from seeking support from superiors and co-workers. Employees may even fear losing their job over an inability to cope with the stressors inherent in their jobs. There can be tragic consequences when employees are afraid to seek treatment or ask managers and co-workers for help. It needs to be recognized that mental illness is a serious crisis for employees, and it demands a serious response from employers. Mental health has to be seen as important as physical health. ${ }^{8}$

\section{Objectives:-}

To assess the level of stress among the staff nurses working in emergency and general wards.

\section{Materials and methods:-}

The Quantitative descriptive approach was used comparative descriptive design was chosen. The settings selected for the study were Emergency wards (Accident/emergency wards (level 1. level 2, level 3), ICU'S, Labor rooms, emergency OT'S) and General wards (medical, surgical Wards, Maternity wards, main OT's). population comprises of all the staff nurses who have been working in emergency wards (ICU'S, Accident/emergency wards (level 1 .level 2, level 3), Labour rooms, emergency OT's) and general wards (medical, surgical wards, Maternity wards, main OT's ). The sample chosen for the present study were the staff nurses who were certified as a GNM OR B.Sc $(\mathrm{N})$ OR Post Basic $(\mathrm{N})$ or M.Sc $(\mathrm{N})$ qualification with professional registration and have been working in the emergency and general wards. 120 staff nurses 60 from each area were selected by using Probability simple random sampling technique. Selection of tool was done by using extensive review literature. Perceived stress scale was used to collect the data.

The perceived stress scale (PSS) was used to assess the level of stress. The PSS is a 14 item, 5point Likert -type scale which measures the degree to which situations in one's appraised is as stressful, assuming centrality of the cognitive appraisal process opposed to or in addition to objective stress (Cohen et al 1983).Items on the instrument were designed to detect the degree to which respondents found their lives un predictable, uncontrolled and overwhelmed. (Cohen et al 1983). Questions in the PSS answered by participants, asked about feelings and thoughts during the last month. The respondents were asked how often they felt a certain way.

The scale includes a number of questions about current levels of stress. This made it an appropriate choice for appraising stress from daily conflicts, major events, and changes in coping resources through a time period of four to eight weeks. Since the scale measures responses that are perceived, it provides a more accurate measure of the level of stress experienced by the respondents. It is the level of appraised stress, not the objective occurrence of events that determine one's response to stress. (Lazarus, 1977).

PSS score are obtained by reversing the scores on the seven positive items, e.g.0=4, $1=3,2=2$, etc. and then summing across all 14 items. Items 4,5,6,7,9,10, and 13 are positively stated items in the questionnaire. (Cohen et al, 1983). Coefficient as ranged from. 84 to 86 with an overall $\alpha$ of .75. Two day and 6 week test- retest correlations have been reported at .85 and.55. respectively. The PSS yields satisfactory concurrent and predictive validity correlating with life -event scores, social anxiety, and both depressive and physical symptoms. collected data was compiled and analyzed by using descriptive and inferential statistics.

\section{Results:-}

Maximum 24 ( 40.0\%) of the staff nurses working in the emergency wards belonged to the age group of less than 30years and $17(28.3 \%)$ were in the age group of 41 to50 years, while as Maximum 28(46.7\%) of the staff nurses working in general wards belonged to the age group of 41 to 50 years and $14(23.3 \%)$ were in the age group of less than 30 years.in emergency wards majority $43(71.6 \%)$ of the staff nurses were married and $17(28.3 \%)$ were unmarried and no divorced staff nurses were found in emergency wards while as majority $45(75 \%)$ of the staff nurses working in general wards were married and 3(5\%) were divorced. Maximum 32(53.3\%) of the staff nurses working in emergency wards were B.sc. Nursing/ Post basics in nursing holders and 01(1.7\%) were M.sc. nursing 
holders. Whereas 36(60\%) of the staff nurses working in general wards were GNM holders and 01(1.6\%) were M.sc. nursing holders. Majority 29 (48.4\%) of the staff nurses working in emergency wards were having experience of 1-8 years and 11(18.3\%) were having 8-16 years of experience. Whereas majority $32(53.3 \%)$ of the staff nurses working in general wards were having experience of 16-24 years and 7 (11.7\%) were having 8-16 years of working experience.

In emergency wards the majority of the sample was from intensive care units (46.70\%) and accident/ emergency wards $(40 \%)$ labour rooms accounted for (10\%) and emergency OTs (3.30\%).In general wards the medical wards accounted for $(40 \%)$; surgical wards accounted for $(33.30 \%)$; theatres accounted for $(15 \%)$ of the response and Maternity wards accounted for $(11.70 \%)$ of the sample response.

Table 1:- Comparison of mean scores of perceived stress of staff nurses working in emergency and general wards of skims hospital

\begin{tabular}{|l|l|l|l|l|l|l|l|l|l|}
\hline $\begin{array}{l}\text { Group } \\
\text { Name }\end{array}$ & $\mathbf{N}$ & Mean & SD & $\begin{array}{l}\text { Mean } \\
\text { Difference }\end{array}$ & $\begin{array}{l}\text { 95.00\% } \\
\text { Interval }\end{array}$ & Confidence & Cal.t & Df & p-Value \\
\hline $\begin{array}{l}\text { Emergency } \\
\text { wards }\end{array}$ & 60 & 27.77 & 7.96 & \multirow{2}{*}{5.35} & $\begin{array}{l}\text { Lower } \\
\text { Limit }\end{array}$ & $\begin{array}{l}\text { Upper } \\
\text { Limit }\end{array}$ & \multirow{2}{*}{3.92} & 118 & $<0.001$ \\
\cline { 1 - 3 } $\begin{array}{l}\text { General } \\
\text { wards }\end{array}$ & 60 & 22.42 & 6.97 & & 2.645 & 8.055 & & \\
\hline
\end{tabular}

Table 1: Presents that staff nurses working in emergency wards differ significantly from staff nurses working in general wards in their stress level as the obtained calculated t-value(3.92) is significant at $p<0.001$.

\section{Two-Sample t-Test}

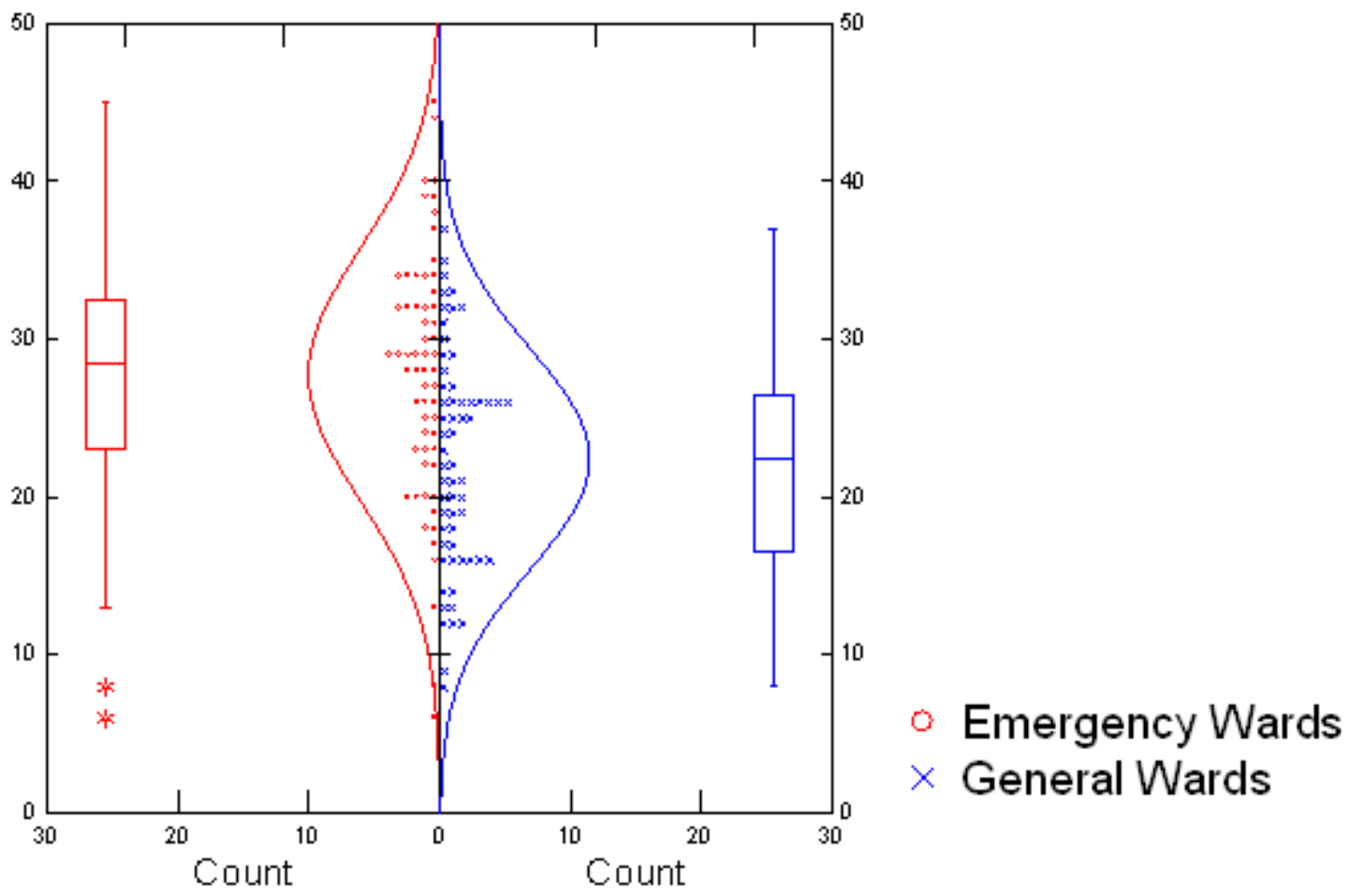

Fig. 1:- 
Table 2:- Frequency distribution \& percentage with respect to levels of stress of staff nurses working in emergency and general wards.

\begin{tabular}{|l|l|l|l|l|}
\hline Group & Levels of stress scores & Frequency & Percentage & p-Value \\
\hline \multirow{3}{*}{ Emergency wards } & Mild $(0-14)$ & 3 & 5.00 & \\
& Moderate $\quad(15-28)$ & 27 & 45.00 & \\
& Severe 29 & 30 & 50.00 & \multirow{2}{*}{0.002 (Sig.) } \\
\hline \multirow{3}{*}{ General wards } & Mild $(0-14)$ & 9 & 15.00 & \\
& Moderate $\quad(15-28)$ & 39 & 65.00 & \\
\hline
\end{tabular}

$\chi_{\text {cal. }}^{2} 12.896$ with 2 degrees of freedom.

Note: The proportions of observations in different columns of the contingency table vary from row to row. The two characteristics that define the contingency table are significantly related. $(\mathrm{P}=0.002<0.05)$

In emergency wards $30(50 \%)$ of staff nurses had severe level of stress, whereas $27(45 \%)$ of staff nurses had moderate level of stress and 3(5\%) were under mild level of stress, while as in general wards majority $39(65 \%)$ of staff nurses had moderate level of stress scores, whereas 12(20\%) were under severe level of stress scores and 9 $(15 \%)$ were under mild level of stress. So, there is significant difference in level of stress between staff nurses working in emergency and general wards $(\mathrm{P}=0.002<0.05)$.

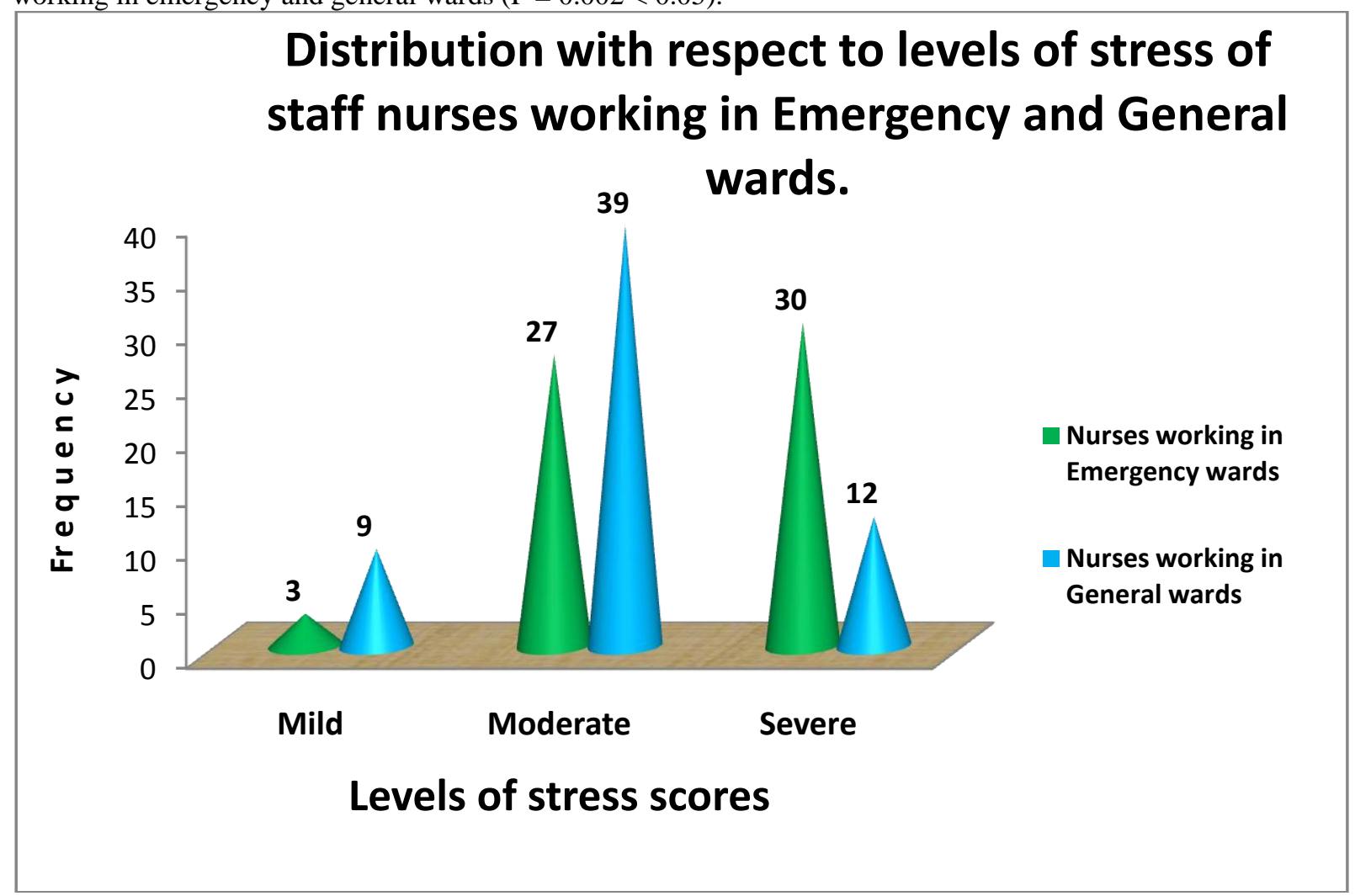

Fig.: 2:- 
Table 3:- Association of levels of stress of staff nurses working in Emergency wards with selected sociodemographic variables

\begin{tabular}{|c|c|c|c|c|c|c|c|}
\hline S. No & $\begin{array}{ll}\begin{array}{l}\text { Socio } \\
\text { variables }\end{array} & \text {-demographic } \\
& \end{array}$ & mild & moderate & Severe & $\begin{array}{l}\text { Chi-square } \\
\text { Calculated }\end{array}$ & $\mathrm{df}$ & P-Value \\
\hline \multirow[t]{4}{*}{1.} & \multicolumn{4}{|l|}{ AGE } & \multirow[t]{4}{*}{5.474} & \multirow[t]{4}{*}{4} & \multirow[t]{4}{*}{0.242} \\
\hline & $<30$ years & $\mathbf{1}$ & 12 & 11 & & & \\
\hline & $31-40$ years & $\mathbf{0}$ & 6 & 14 & & & \\
\hline & $41-50$ years & 2 & 7 & 7 & & & \\
\hline \multirow[t]{3}{*}{2.} & \multicolumn{4}{|l|}{ MARRIATAL STATUS } & \multirow[t]{3}{*}{4.509} & \multirow[t]{3}{*}{2} & \multirow[t]{3}{*}{0.105} \\
\hline & MARRIED & 2 & 16 & 28 & & & \\
\hline & UNMARRIED & 1 & 9 & 4 & & & \\
\hline \multirow[t]{4}{*}{3.} & \multicolumn{4}{|c|}{ PROFESSIONAL QUALIFICATION } & \multirow[t]{4}{*}{3.379} & \multirow[t]{4}{*}{4} & \multirow[t]{4}{*}{0.497} \\
\hline & GNM & $\mathbf{0}$ & 12 & 13 & & & \\
\hline & $\begin{array}{ll}\text { BSC/POST } & \text { BASICS } \\
\text { NURSING } & \end{array}$ & 3 & 15 & 16 & & & \\
\hline & MSC NURSING & $\mathbf{0}$ & $\mathbf{0}$ & 1 & & & \\
\hline \multirow[t]{4}{*}{4.} & \multicolumn{4}{|c|}{ WORKING EXPERIENCE ( Years) } & \multirow[t]{4}{*}{2.938} & \multirow[t]{4}{*}{4} & \multirow[t]{4}{*}{0.568} \\
\hline & $1-8$ & 1 & 14 & 14 & & & \\
\hline & $8-16$ & $\mathbf{0}$ & 5 & 7 & & & \\
\hline & $16-24$ & 2 & 6 & 11 & & & \\
\hline \multirow[t]{5}{*}{5.} & \multicolumn{4}{|l|}{ WORKING AREA } & \multirow[t]{5}{*}{20.07} & \multirow[t]{5}{*}{6} & \multirow[t]{5}{*}{$<0.001$} \\
\hline & $\begin{array}{l}\text { ACCIDENT } \\
\text { EMERGENCY }\end{array}$ & $\mathbf{1}$ & 4 & 19 & & & \\
\hline & ICU'S & 2 & 16 & 10 & & & \\
\hline & LABOUR ROOM & $\mathbf{0}$ & 6 & $\mathbf{0}$ & & & \\
\hline & EMERGENCY O'S & $\mathbf{0}$ & $\mathbf{0}$ & 2 & & & \\
\hline
\end{tabular}

Note: There was no respondent of divorced and widowed category hence both the rows has been excluded from the above table.

* Since the p-value is (0.242) which is more than 0.005 significance level, hence there is no association between the level of stress and age of staff nurses working in emergency wards.

* Since the p-value is $(0.105)$ which is more than 0.005 significance level, hence there is no association between the level of stress and marital status of staff nurses working in emergency wards.

* The p- value (0.497) for professional qualification that is $\mathrm{p}>0.05$ level of significance hence there is no association between the levels of stress and the professional qualification of the staff nurses.

* The p-value (0.568) for working experience that is $>0.05$ level of significance hence there is no association between the levels of stress and the for working experience of the staff nurses.

* The p- value $(<0.001)$ for working area at 0.05 level of significance hence there is significant association between the levels of stress and working area of the staff nurses.

Table 4:- Association of levels of stress of staff nurses working in General wards with selected sociodemographic variables

\begin{tabular}{|c|c|c|c|c|c|c|c|}
\hline S. No & $\begin{array}{ll}\text { Socio } \\
\text { variables }\end{array}$ & mild & moderate & Severe & $\begin{array}{l}\text { Chi-square } \\
\text { Calculated }\end{array}$ & Df & P-Value \\
\hline \multirow[t]{4}{*}{1.} & \multicolumn{4}{|l|}{ AGE } & \multirow[t]{4}{*}{3.458} & \multirow[t]{4}{*}{4} & \multirow[t]{4}{*}{0.484} \\
\hline & $<30$ years & 1 & 10 & 3 & & & \\
\hline & $31-40$ years & 5 & 10 & 3 & & & \\
\hline & $41-50$ years & 3 & 20 & 5 & & & \\
\hline \multirow[t]{4}{*}{2.} & \multicolumn{4}{|l|}{ MARIATAL STATUS } & \multirow[t]{4}{*}{3.624} & \multirow[t]{4}{*}{4} & \multirow[t]{4}{*}{0.459} \\
\hline & MARRIED & 8 & 30 & 8 & & & \\
\hline & UNMARRIED & 0 & 8 & 3 & & & \\
\hline & DIVORCED & 1 & 2 & 0 & & & \\
\hline \multirow[t]{2}{*}{3.} & \multicolumn{4}{|l|}{ QUALIFICATION } & \multirow[t]{2}{*}{1.632} & \multirow[t]{2}{*}{4} & \multirow[t]{2}{*}{0.803} \\
\hline & GNM & 7 & 22 & 8 & & & \\
\hline
\end{tabular}




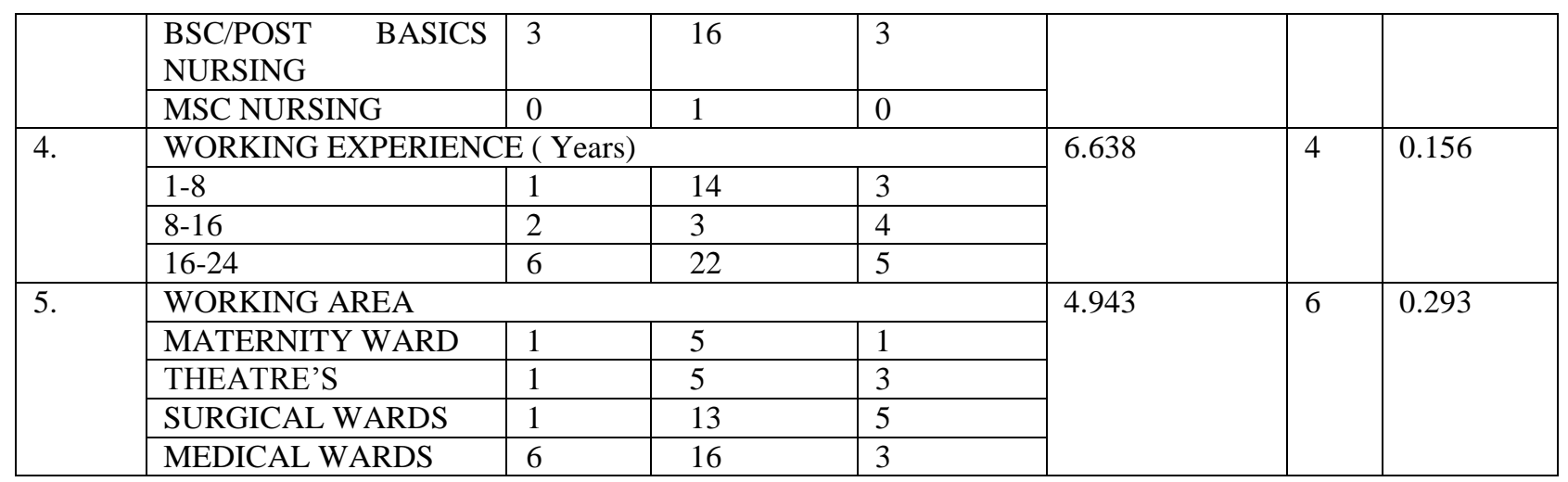

* since the p-value is (0.484) which is more than 0.005 significance level, hence there is no association between the level of stress and age of staff nurses.

* The p-value is $(0.459>0.05)$ level of significance hence there is no association between the levels of stress and the marital status of the staff nurses.

* The p- value is $(0.803)$ for professional qualification that is $p>0.05$ level of significance hence there is no association between the levels of stress and the professional qualification of the staff nurses.

* The p-value $(0.156>0.05)$ level of significance hence there is no association between the levels of stress and the for working experience of the staff nurses.

* p- value (0.293) for working area at 0.05 level of significance hence there is no association between the levels of stress and

* working area of the staff nurses.

\section{Discussion:-}

This study suggests that perceived level of stress varies within different work settings of same hospital. Perceived stress levels were found to be higher in emergency wards The mean levels of stress score was in emergency wards was 27.77 and the standard deviation was 7.96 where as the mean levels of stress score in general wards was 22.42 and the standard deviation was 6.97. In general wards majority $39(65 \%)$ of staff nurses had moderate level of stress scores, whereas $12(20 \%)$ were under severe level of stress and $9(15 \%)$ were under mild level of stress. In emergency wards $30(50 \%)$ of staff nurses had severe level of stress, whereas $27(45 \%)$ of staff nurses had moderate level of stress and $3(5 \%)$ were under mild level of stress. so, there is significant difference in level of stress between staff nurses working in emergency and general wards $(\mathrm{P}=0.002<0.05)$.

The findings of the study are supported by a study conducted By Keese K S ${ }^{9}$ in1993 in Kirkhof School of Nursing. The findings revealed that there was a significant difference in stress scores between medical-surgical staff nurses and critical care staff nurses $[\mathrm{t}(\mathrm{OOO})=-3.51, \mathrm{p}<.001]$. Medical-surgical staff nurses perceived higher levels of stress.

The association between the levels of the stress scores and the selected socio demographic variables was computed using chi-square(x2) test. There is no significant association of socio demographic values like age, marital status, and professional qualification, working experience and working area with stress level of staff nurses working in general wards. Whereas, the few socio demographic values of staff nurses working in emergency wards, showing no association between level of stress with age, marital status, professional qualification, and working experience but shows significant association of level of stress with working area of staff nurses at 0.05 significant level.

A descriptive study conducted by Varghese S. ${ }^{10}$ in 2013."to assess the level of stress and coping mechanisms among nurses working in intensive care units". The findings revealed that $\chi 2 \mathrm{cal} .<$ Tab. value for all demographic variables hence no association between stress levels with socio-demographic variables.

Another finding of the study are supported by a study conducted by Keese K S. ${ }^{9}$ in 1993 "to compare perceived stress levels of registered nurses employed in medical-surgical units to perceived stress levels of registered nurses employed in critical care units". The findings revealed that there was no relationship between years of nursing education and job stress scores at the $\mathrm{p}<.05$ level using Spearman's Correlation (rho $=-.1055, \mathrm{p}=.29$ ). There was 
essentially no relationship demonstrated at the $\mathrm{p}<.05$ level between years of experience and stress scores, $\mathrm{r}=-.1479$, $\mathrm{E}=.069$.

\section{Conclusion:-}

In emergency wards majority of staff nurses had severe level of stress whereas in general wards majority of staff nurses had moderate level of stress. There was no association between level of stress with socio-demographic values like age, marital status, and professional qualification, working experience and working area of staff nurses working in general wards. There was no association between level of stress with socio-demographic values like age, marital status, and professional qualification and working experience but shows significant association of level of stress with working area of staff nurses working in emergency wards.

\section{References:-}

1. C Viji Prasad1, Amrutha Suresh2, Dina K Thomas2, MK Pritty2, Sumaida Beebi2, Vijapura The level of stress and coping mechanism adopted by I Year B.Sc. nursing students. Archives of medicine and health sciences.2013;1(1):19-23

2. Arash Najimi, , Ali Moazemi Goudarzi, ${ }^{2}$ and Gholamreza Sharifirad, Causes of job stress in nurses: A crosssectional studyIran J Nurs Midwifery Res. 2013 ;17(4): 301-305.

3. Steven S. Work place stress. Centers for disease control and prevention (CDC): NOISH; 2007 Dec 3rd.

4. Mathew AP, Prabhakar A. Job stress perception among nurses. The nursing journal of India. 2004; 110(5):105107.

5. Vacho ML. Burnout and symptoms of stress in staff working in palliative care. Handbook of Psychiatry in Palliative Medicine. New York; 2000: 303-19.

6. Richard T. The patient within psychopathology- in the helping profession. National Health Service Report. 1997; 3(5): 278-281.

7. Cox T, Griffiths A. Work-related stress in nursing: controlling the risk to health [research work]. Geneva: University of Nottingham; 1996.

8. Harvey R. Depression costs business, The Edmonton Sun. 2005 Apr 15

9. Karen S. K. Perceived Stress Levels of Registered Nurse Employed in Medical-Surgical and Critical Care Units [M.Sc (N) Thesis]. Allendale USA: Grand Valley State University; 1993: http://scholarworks.gvsu.edu/theses

10. Varghese S. To assess the level of stress and coping mechanisms among nurses working in intensive care units [M.Sc (N) Dissertation]. Belgaum: K L E University Belgaum; 2013. 